Conrad Buol

Heinrich Pestalozzi 
Conrad Buol

\section{Heinrich Pestalozzi}

ausgewählte Texte für die

Lehrerbildung, Erziehungspraxis

und Sozialarbeit

Springer Basel AG 
CIP-Kurztitelaufnahme der Deutschen Bibliothek

\section{Pestalozzi, Johann Heinrich}

[Sammlung]

Heinrich Pestalozzi: ausgew. Texte für d. Lehrer-

bildung u. Erziehungspraxis u. Sozialarbeit/Conrad

Buol. - 1. Aufl. - Basel, Stuttgart: Birkhäuser,

1976.

Nachdruck verboten

Alle Rechte, insbesondere das der Übersetzung in fremde Sprachen und der Reproduktion auf

photostatischem Wege oder durch Mikrofilm, vorbehalten.

ISBN 978-3-7643-0884-1

ISBN 978-3-0348-6597-5 (eBook)

DOI 10.1007/978-3-0348-6597-5

(C) Springer Basel AG 1976

Ursprünglich erschienen bei Birkhäuser Verlag Basel 1976. 


\section{Inhaltsverzeichnis}

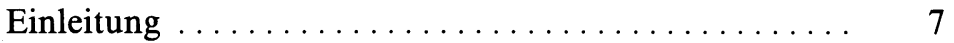

J.H. Pestalozzi, eine Kurzbiographie $\ldots \ldots \ldots \ldots \ldots, \quad 12$

Quellentexte .......................... 24

I. Wohn- und Schulstuben, Schulmeister

Von Wohn- und Schulstuben $\ldots \ldots \ldots \ldots \ldots \ldots .25$

Vom Lirilariwesen in der Schule ................. $\quad 28$

Der rechte Schulmeister .................... . 30

\section{Zum Wesen des Menschen}

Was ist der Mensch ...................... 33

Der Mensch, ein zwiespältiges Wesen, ein Ring in der Kette .............................. $\quad 35$

Zur Entwicklung der Menschheit ............... 37

Der Mensch im Naturzustand $\ldots \ldots \ldots \ldots \ldots \ldots . \quad 38$

Der Mensch in der kollektiven Existenz . . . . . . . $\quad 40$

Der sittlich-selbständige Mensch . . . . . . . . . . . . 44

Von der Freiheit $\ldots \ldots \ldots \ldots \ldots \ldots \ldots \ldots \ldots \ldots \ldots \ldots$

\section{Menschenbildung}

Erfahrungen als Waisenvater $\ldots \ldots \ldots \ldots \ldots \ldots . \quad 51$

Vertrauen in die Anlagen auch unter ungünstigen

Umständen .......................... 51

Stille und Gewöhnung als Mittel der Disziplin .... 52

Gemütsstimmung, Erfahrung und Tun als Grundlagen der Menschenbildung ................ 53

Strafen und sittliche Elementarbildung $\ldots \ldots \ldots . \quad 56$

Über Schlittschuhlaufen und körperliche Züchtigung ... 59

Zur Entwicklung der Geisteskräfte ................ 61

Zur religiösen Bildung ...................... 64

Kraftbildung - Kunstbildung ................ 70

Von dreierlei Bestien und Eseln - oder von einseitiger Bildung ........................... 72

Die Würde als Mittel und Ziel der Menschenbildung . . 74 
Erhebung zur Menschlichkeit durch Liebe $\ldots \ldots \ldots \ldots .76$

Das Bild des Baumes für Werden und Bildung des Menschen ......................... 78

Herz, Geist und Hand und die einigende Gemeinkraft . . 82

\section{Anhang}

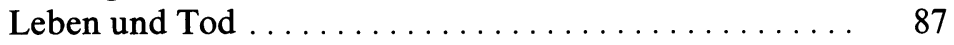

Aus Briefen Pestalozzis . . . . . . . . . . . . . . . . . 89

Niederschrift und letzte Willenserklärung . . . . . . . . 95

Aus Berichten von Zeitgenossen Pestalozzis . . . . . . . 97

Didaktische Hinweise . . . . . . . . . . . . . . . . 105 